\title{
A CONTRIBUIÇÃO DE PROCESSOS DE ENSINO E APRENDIZAGEM COM PESQUISA NA FORMAÇÃO DE PROFESSORES E ALUNOS DA EDUCAÇÃO BÁSICA
}

\author{
Janice Silvana Novakowski Kierepka * \\ Roque Ismael da Costa Güllich ** \\ Lenir Basso Zanon ***
}

\begin{abstract}
Resumo: Neste texto, relataremos experiência vivenciada no desenvolvimento de um projeto inserido no PICMEL da FAPERGS. O projeto foi desenvolvido de outubro de 2014 a novembro de 2015, em uma escola na cidade de Guarani das Missões/RS, em parceria com a Universidade Federal da Fronteira Sul (UFFS), Campus Cerro Largo/RS, intitulado: "A pesquisa científicoescolar na Educação Básica e reconhecimento da área de Ciências Biológicas”. Serão descritas a constituição do grupo, os objetivos almejados, as ações abrangidas no programa, bem como discutidas algumas contribuições do programa à formação dos alunos e professores, depreendidas a partir da investigação de diários de bordo de integrantes do grupo. Defendemos que o diário de bordo pode ter contribuído, por meio da reflexão, no processo de internalização de conceitos e formas de pesquisar, à medida que identificamos indícios da reconstrução de concepções de pesquisa com base na perspectiva do Educar pela Pesquisa: valorização do protagonismo do aluno; na reconstrução dos conhecimentos; com o professor como orientador da pesquisa; no resgate da autonomia do aluno; para o levantamento das curiosidades formuladas pelos alunos, a leitura e a escrita. Desse modo, identificamos indícios de pressupostos que norteiam o Educar pela Pesquisa, o que aponta para a possibilidade de utilizálo para a transformação das concepções de professores em formação continuada, com a superação de visões tradicionais, e nos permite reafirmar também a relevância de grupos de formação continuada, enquanto espaços que auxiliam na transformação de concepções de docência e quiçá de práticas pedagógicas.
\end{abstract}

Palavras-chaves: Educar pela Pesquisa. Diário de bordo. Reflexão. Internalização.

\section{Considerações Iniciais}

Neste texto, temos a finalidade de relatar a experiência vivenciada no desenvolvimento de um projeto inserido no Programa de Iniciação em Ciências, Matemática, Engenharias, Tecnologias Criativas e Letras (PICMEL) da Fundação de Apoio à Pesquisa do Rio Grande do Sul (FAPERGS). Serão descritas a constituição do grupo, os objetivos almejados, as ações abrangidas no programa, bem como discutidas algumas contribuições do programa à formação dos alunos e professores, depreendidas a partir da investigação de diários de bordo de integrantes do grupo.

\footnotetext{
* Professora de Educação Básica. Mestre em Educação nas Ciências

${ }^{* *}$ Universidade Federal da Fronteira Sul. Doutor em Educação nas Ciências

${ }^{* * *}$ Universidade Regional do Noroeste do Estado do Rio Grande do Sul. Doutora em Educação nas Ciências.
} 
O projeto inserido no âmbito do PICMEL foi desenvolvido em uma escola na cidade de Guarani das Missões, Estado do Rio Grande do Sul (RS), em parceria com a Universidade Federal da Fronteira Sul (UFFS), Campus Cerro Largo/RS, intitulado: “A pesquisa científicoescolar na Educação Básica e reconhecimento da área de Ciências Biológicas”. O PICMEL é um Programa de Iniciação em Ciências, Matemática, Engenharias, Tecnologias Criativas e Letras, que tem “o objetivo de despertar vocação científica e incentivar talentos potenciais em alunos do ensino público, fundamental ou médio do RS” (FAPERGS/CAPES, 2014, p. 1).

O projeto PICMEL aqui analisado teve início em outubro de 2014, com término em novembro de 2015, e surgiu porque a proposta do Ensino Médio Politécnico (EMP) já existia há três anos e estava em vigência na escola alvo, que pretendia estimular a pesquisa no ensino. Dessa forma, foi importante desenvolver um projeto sobre esta temática, envolvendo alunos e professores da Educação Básica, os quais pudessem reconhecer essa possibilidade de ensino e aprendizagem. Assim, foi elaborada e submetida ao PICMEL/FAPERGS a proposta, e, após ter sido aprovada, iniciamos o desenvolvimento das atividades pelo grupo.

\section{O caminho e o caminhar na Pesquisa (Metodologia)}

Por ocasião do início das atividades de interação e formação no contexto do PICMEL, foi solicitado o consentimento para participar da investigação, por parte dos sujeitos de pesquisa, quais sejam: duas professoras supervisoras bolsistas (identificadas neste texto como "Sabrina" e "Sandra"), uma professora formadora da escola, identificada como "Paula" (a própria professora pesquisadora participante, autora neste texto) e seis estudantes de Educação Básica bolsistas do PICMEL (identificadas como "Maria", "Milena", "Miriam”, "Franciele", "Fernanda" e "Fabiana"). No projeto, estavam envolvidos também um professor orientador/formador da UFFS e duas licenciandas bolsistas do programa PIBID Ciências Biológicas (voluntárias do projeto inserido no PICMEL).

Foi realizada a investigação dos diários de bordo dos sujeitos de pesquisa. Estes foram escritos durante todos os 14 meses de desenvolvimento do projeto, durante ou após os encontros e leituras. Fizemos uso do diário de bordo por acreditarmos em seu potencial formativo pelo estímulo da reflexão (PORLÁN; MARTÍN, 2001). Primeiramente, foi realizada a leitura dos diários. Logo após, procedemos com a seleção, a demarcação e a digitação de trechos das narrativas que continham indícios de marcas do processo formativo pela via da reflexão. A investigação seguiu abordagem qualitativa de pesquisa, a partir da análise temática dos conteúdos, conforme Lüdke e André (2011), sendo que para a análise utilizamos os marcos teóricos da perspectiva histórico-cultural (VYGOTSKY, 2007; 2008). 
Foram analisados os diários de bordo das professoras supervisoras e das estudantes, pois nosso interesse era situar a pesquisa em contexto escolar, reconhecendo a importância da problematização e de Educar pela Pesquisa na formação docente e no ensino e aprendizagem de Ciências. Julgamos interessante reconhecer e discutir as concepções das Estudantes, especialmente quanto às teorias de ensino subjacentes às práticas educativas dos professores sobre o Educar pela Pesquisa, pois defendemos que as concepções dos estudantes influenciam a relevância e aceitação da pesquisa como forma de aprendizagem.

Cabe registrar que a presente pesquisa foi desenvolvida de maneira a contemplar todos os preceitos éticos contidos na Resolução 466/12, do Conselho Nacional de Pesquisa, do Ministério da Saúde, no que se refere à pesquisa envolvendo seres humanos. A condição de participação como sujeito de pesquisa foi ser participante do PICMEL de uma escola pública estadual do município de Guarani das Missões/RS. Utilizamos o termo de consentimento livre e esclarecido (TCLE), resguardando o sigilo dos sujeitos de pesquisa e a garantia de retirar o consentimento e informações a qualquer momento, se desistir da participação.

Tendo sido consentida a pesquisa, iniciamos analisando os diários de bordo dos sujeitos de pesquisa, produzidos como aporte para a descrição e reflexão sobre as vivências no projeto. A investigação dos diários de bordo dos sujeitos de pesquisa despertou nosso interesse em duas professoras supervisoras bolsistas e seis Estudantes de Educação Básica bolsistas do PICMEL, pois o processo de aprendizagem da pesquisa mostrou ser relevante, à medida que acompanharam todo o processo de execução do projeto (outubro de 2014 a novembro de 2015), configurando-se em um espaço-tempo singular de reflexão individual. Dessa forma, analisando os diários de bordo, foi possível construir indícios do objeto de análise.

\section{Sobre o grupo do PICMEL, as ações abrangidas no projeto e as primeiras aprendizagens do processo}

Para o desenvolvimento semanal das atividades do projeto na Escola, o grupo foi dividido. Um era composto por três estudantes do Ensino Fundamental (nono ano), uma professora supervisora e uma licencianda. O outro era formado por três Estudantes do Ensino Médio (primeiro e segundo ano), uma Professora Supervisora e uma licencianda. Mensalmente, eram realizadas reuniões entre as duas professoras supervisoras, a professora formadora da escola e o professor orientador do projeto, docente da UFFS, Campus Cerro Largo/RS, para o planejamento, a sistematização das atividades e dos resultados de cada grupo, a avaliação e reflexão acerca do desenvolvimento das atividades. 
As seis Estudantes Bolsistas do projeto inserido no PICMEL eram estudantes de Educação Básica, três do Ensino Fundamental e três do Ensino Médio, situando-se o projeto em contexto escolar, conforme objetivo do PICMEL. As professoras supervisoras selecionadas para orientação das estudantes na escola eram docentes da área das Ciências, uma vez que o projeto buscava articular também a área de Ciências Biológicas.

Tendo em vista o objetivo do programa (o qual tinha como foco a formação dos alunos), acreditamos que seja importante apresentar as ações abrangidas no projeto (Quadro 1) que possibilitaram a inserção dos alunos no projeto apresentado pelo seu proponente (professor da Universidade) à FAPERGS/CAPES. As atividades foram planejadas mensalmente. Para sua execução, eram realizados encontros semanais do grupo, na Escola ou na UFFS.

Quadro 1 - Ações abrangidas no projeto do PICMEL.

\begin{tabular}{|c|c|}
\hline Mês e Ano & Ações \\
\hline $\begin{array}{l}\text { Outubro c } \\
2014\end{array}$ & $\begin{array}{l}\text { Neste mês, iniciaram-se as atividades do projeto. Foi realizado o primeiro encontro do grupo, } \\
\text { com: apresentação das estudantes bolsistas e das professoras supervisoras; leitura do projeto } \\
\text { "Pesquisa científico-escolar na educação básica e reconhecimento da área de Ciências } \\
\text { Biológicas"; descrição das atividades que foram desenvolvidas no projeto; apresentação da } \\
\text { finalidade da FAPERGS através de um vídeo institucional. Em outro encontro, o grupo } \\
\text { participou do IV Seminário de Ensino, Pesquisa e Extensão realizado pela UFFS e em uma } \\
\text { reunião com o professor coordenador do projeto na UFFS. No mesmo mês, foi realizada a } \\
\text { organização do laboratório de Ciências da Escola, com o desenvolvimento de atividades } \\
\text { experimentais. As atividades desenvolvidas eram descritas e refletidas pelo grupo de forma } \\
\text { individual no diário de bordo. }\end{array}$ \\
\hline $\begin{array}{l}\text { Novembro de } \\
2014\end{array}$ & $\begin{array}{l}\text { Detalhamento do projeto por meio de leitura e discussão acerca dos objetivos e metodologia do } \\
\text { projeto. Nos outros encontros do mês, foi realizada a leitura e discussão do artigo "Educar pela } \\
\text { Pesquisa: exercício de aprender a aprender", de autoria de MORAES (2002). As reflexões sobre } \\
\text { as leituras eram realizadas também individualmente no diário de bordo. }\end{array}$ \\
\hline $\begin{array}{l}\text { Dezembro de } \\
2014\end{array}$ & $\begin{array}{l}\text { Leitura e discussão dos textos: "Pesquisa como superação da aula copiada" (FRISON, 2002) e } \\
\text { "Pesquisa em sala de aula: tendências para a Educação em novos tempos" (MORAES, 2002). } \\
\text { Foram distribuídas para cada aluna uma apostila com textos para leitura durante as férias. }\end{array}$ \\
\hline $\begin{array}{l}\text { Janeiro e } \\
\text { fevereiro de } \\
2015\end{array}$ & $\begin{array}{l}\text { Tarefa para casa: realização de leituras dos textos sobre pesquisa na escola (MORAES, 2002; } \\
\text { MORAES; GALIZZI; RAMOS, 2002; RAMOS, 2002). Reflexões no diário de bordo sobre as } \\
\text { leituras realizadas. }\end{array}$ \\
\hline Março de 2015 & $\begin{array}{l}\text { Nos primeiros dois encontros, realizaram-se discussões sobre as leituras no recesso escolar. } \\
\text { Descrição, proposta pelo Professor Formador/Orientador da UFFS, no diário de bordo sobre o } \\
\text { que é pesquisa como alternativa para a construção de indícios de concepções sobre pesquisa. }\end{array}$ \\
\hline
\end{tabular}




\begin{tabular}{|c|c|}
\hline Mês e Ano & Ações \\
\hline & $\begin{array}{l}\text { Recebimento, pela escola, dos materiais do programa do PICMEL para o desenvolvimento do } \\
\text { projeto. }\end{array}$ \\
\hline$A b r$ & $\begin{array}{l}\text { Leitura e discussão pelo grupo do Regimento Referência das Escolas de Ensino Médio } \\
\text { Politécnico da Rede Estadual e comparação com o Regimento Escolar da Escola. Reflexão no } \\
\text { diário de bordo sobre a análise destes documentos. Realização de atividades experimentais com } \\
\text { o material adquirido pelo projeto para o laboratório de Ciências da escola. Leitura e fichamento } \\
\text { no diário de bordo do livro: "Pesquisa na escola: o que é, como se faz?" (BAGNO, 2009). }\end{array}$ \\
\hline 2015 & $\begin{array}{l}\text { Foi realizada uma busca de artigos relacionados com pesquisa na escola no site da Scientific } \\
\text { Electronic Library Online (SciELO) e no Encontro Investigação na Escola pelas seis estudantes } \\
\text { da educação básica e as duas professoras supervisoras, auxiliadas pelo professor } \\
\text { orientador/formador da UFFS, a professora formadora da escola (a própria professora } \\
\text { pesquisadora participante, autora deste texto) e as duas licenciandas do programa PIBID } \\
\text { Ciências Biológicas, voluntárias do projeto. Também foi realizada uma busca das teses sobre a } \\
\text { temática no Banco da CAPES, datadas a partir do ano de } 2008 \text {. Houve, então, a construção de } \\
\text { uma tabela para a categorização dos resultados construídos com base na coleta de dados realizada } \\
\text { no site SciELO, Banco de teses da CAPES e Encontro Investigação na escola. Após a } \\
\text { organização da tabela, foi escrito um artigo para a discussão dos resultados. Descrição e reflexão } \\
\text { no diário de bordo sobre esse processo de pesquisa. }\end{array}$ \\
\hline 2015 & $\begin{array}{l}\text { Curso realizado pelo Serviço Nacional de Aprendizagem Rural (SENAR) sobre educação } \\
\text { ambiental, que teve a participação de todos os estudantes do Ensino Médio da Escola onde o } \\
\text { projeto inserido no PICMEL foi desenvolvido, além do grupo constituinte do projeto. No } \\
\text { primeiro dia, foram abordados os seguintes assuntos: discussão sobre a água, solo, resíduos } \\
\text { sólidos, agrotóxicos; como fazer uma composteira; limpeza de caixa-d'água; inseticidas } \\
\text { caseiros. No segundo dia, a palestrante discutiu sobre os procedimentos para fazer sabão, } \\
\text { amaciante e desinfetante caseiro. } \\
\text { Elaboração dos resumos enviados ao V Seminário de Ensino, Pesquisa e Extensão (SEPE). } \\
\text { Apresentação do trabalho intitulado "Pesquisa Científico-Escolar na Educação Básica através } \\
\text { do PICMEL FAPERGS", na modalidade pôster, no IX Congresso Latino-americano } \\
\text { Interdisciplinar Orientado ao Adolescente (CICLOA), evento realizado em Porto Alegre/RS. } \\
\text { Descrição e reflexão no diário de bordo sobre o curso, produções e participação em eventos. }\end{array}$ \\
\hline Julho de 2015 & eríodo de recesso escolar. \\
\hline $\begin{array}{l}\text { Agosto de } \\
2015\end{array}$ & $\begin{array}{l}\text { Apresentação do trabalho intitulado "Um olhar para a pesquisa científico-escolar na educação } \\
\text { básica a partir do PICMEL" no XIII Encontro Investigação na escola. Leitura, discussão e } \\
\text { reflexão no diário de bordo sobre o livro "Ensinar e aprender com a pesquisa no Ensino médio". } \\
\text { Foram realizadas oficinas sobre apresentação de trabalhos utilizando power point e prezi. }\end{array}$ \\
\hline $\begin{array}{l}\text { Setembro } \\
2015\end{array}$ & $\begin{array}{l}\text { Apresentação do trabalho intitulado "A Pesquisa escolar no Ensino de Ciências: uma } \\
\text { reconstrução de aprendizagens a partir da problematização, construção de argumentos e } \\
\text { comunicação" na XX Jornada de Pesquisa, evento realizado no Salão do Conhecimento da }\end{array}$ \\
\hline
\end{tabular}




\begin{tabular}{|c|c|}
\hline Mês e Ano & Ações \\
\hline & $\begin{array}{l}\text { Unijuí/Campus Ijuí. Oficina sobre métodos de confeccionar banner. Descrição e reflexão no } \\
\text { diário de bordo sobre a participação na XX Jornada de Pesquisa. }\end{array}$ \\
\hline $\begin{array}{l}\text { Outubro } \\
2015\end{array}$ & $\begin{array}{l}\text { Apresentação dos trabalhos intitulados: "O Ensino Médio Politécnico e a Pesquisa na Educação } \\
\text { Básica" e "A Pesquisa Escolar e o Educar pela Pesquisa no Ensino de Ciências" no V Seminário } \\
\text { de Ensino, Pesquisa e Extensão (V SEPE), evento realizado na UFFS, Campus Cerro Largo/RS. } \\
\text { Descrição e reflexão no diário de bordo sobre a participação no SEPE. Leitura do projeto inserido } \\
\text { no PICMEL para avaliação das ações planejadas e desenvolvidas. Leitura do texto "Educar pela } \\
\text { Pesquisa: exercício de aprender a aprender" (MORAES, 2002) para discussão. Produção pelo } \\
\text { grupo do relatório final do projeto. }\end{array}$ \\
\hline $\begin{array}{l}\text { Novembro de } \\
2015\end{array}$ & $\begin{array}{l}\text { Encontro de confraternização entre as estudantes bolsistas, professoras supervisoras, professor } \\
\text { orientador/formador da UFFS, professora formadora da escola (a própria professora } \\
\text { pesquisadora participante, autora deste texto) e licenciandas do programa PIBID Ciências } \\
\text { Biológicas, voluntárias do projeto. Encerramento do projeto. }\end{array}$ \\
\hline
\end{tabular}

Fonte: Elaborado pelos autores.

Em termos de aprendizagens iniciais, percebemos que as licenciandas voluntárias tinham experiência de pesquisa prévia. Dessa forma, a participação nesse grupo tornou possível a constituição da experiência de refletir e pesquisar a própria prática, com aporte em leituras de produções acadêmicas da pesquisa educacional que consubstanciam a produção do professor na Escola. Nesse sentido, a licencianda, além de pesquisar o grupo, também participava como sujeito em formação no mesmo processo de investigação-ação. Assim, se constituía em investigadora nos moldes da academia e pesquisa de práticas docentes. Essa é uma articulação importante na constituição da professora pesquisadora, que dialoga com a teoria e a prática, em que a união dialética das duas possibilita a produção do conhecimento do professor (CARR; KEMMIS, 1988).

Também podemos afirmar que o PIBID Ciências Biológicas, além de introduzir os licenciandos no contexto escolar, proporcionando a experiência de ensino desde os primeiros semestres da graduação, também estimula a reflexão sobre essas práticas, com a finalidade de constituir sujeitos professores pesquisadores da própria prática, o que foi peça fundamental no processo que analisamos.

Os Ciclos Formativos no Ensino de Ciências se desenvolvem com aporte na investigação-formação-ação. Os licenciandos do PIBID e supervisoras da escola participavam deste coletivo, juntamente com outros licenciandos e professores formadores da Universidade, como sujeitos ativos, em constante formação. Neste coletivo, os sujeitos são incentivados a produzir relatos de experiência sobre suas práticas, em que são descritas e refletidas, 
constituindo-se em uma autêntica investigação da prática com aporte em teorias. Dessa forma, os sujeitos da escola e licenciandos podem se reconhecer produtores de conhecimento para si e para os outros, uma vez que também eram compartilhados por meio da publicação de relatos de experiência. Assim, além da experiência em pesquisa constituída em projetos de iniciação científica, as licenciandas voluntárias do grupo constituído pelos integrantes do projeto inserido no PICMEL tiveram a oportunidade de experimentar a pesquisa a partir da própria prática.

Dessa forma, as licenciandas, assim como a autora deste trabalho (professora formadora da escola), possuíam experiência em pesquisa, constituindo-se relações assimétricas que eram importantes no grupo, à medida que o indivíduo aprende na interação com outro mais experiente. Segundo Vygotsky (2008), o ser humano aprende por meio da interação social, ganhando ênfase na importância das experiências sócio-interacionistas na constituição do sujeito. Zanon (2003) propõe a constituição de tríades de interação, que no programa do PICMEL envolveram professores de escola e da universidade, estudantes da Educação Básica e licenciandas. Chaves e Aragão (2001, p.1) propõem que se constituam “diálogos assimétricos, porém não hierárquicos entre professores e formadores na constituição de práticas de formação docente que possibilitem redimensionamento e transformações", estando todos os sujeitos em processo de formação. Essas relações assimétricas devem impulsionar a constituição dos sujeitos.

Nesse sentido, a professora formadora da escola e as duas licenciandas voluntárias tinham como finalidade instigar o grupo ao diálogo e reflexão sobre teorias e práticas, gerando mais assimetria favorável, ao mesmo tempo em que realizavam sua formação inicial e continuada. Desse modo, buscaram exercer o papel de amigo crítico, que em "relações colaborativas, [...] ajuda aos 'atores' para que ajam com mais sabedoria, prudência e sentido crítico no processo de transformar a educação" (CARR; KEMMIS, 1988, p. 173). Assim, defendemos que a participação desses sujeitos poderia auxiliar no aprendizado do processo de pesquisa pelos demais sujeitos, bem como na apropriação do Educar pela Pesquisa. Naquele contexto, a participação almejada era colaborativa, baseada na acepção de Ibiapina (2008, p. 26), que define a pesquisa-ação colaborativa como diferenciada das outras, especialmente pela "valorização das atitudes de colaboração e reflexão crítica, visto que os pares, calcados em decisões e análises construídas por meio de negociações coletivas, tornam-se [...] coautores de processos investigativos delineados a partir da participação ativa”. Dessa forma, o grupo se constituía em pressupostos da investigação-ação/investigação-formação ação, como preconiza Güllich (2013). 
O projeto inserido no PICMEL buscou o envolvimento ativo dos participantes no processo de pesquisa, de maneira em que todos se reconhecessem como sujeitos no processo de pesquisa. Portanto, tínhamos como intuito constituir um grupo participativo, estimulador da capacidade reflexiva, que "necessita de contextos que favoreçam o seu desenvolvimento", pois "é preciso fazer um esforço grande para passar do nível meramente descritivo ou narrativo para o nível em que se buscam interpretações articuladas e justificadas e sistematizações cognitivas" (ALARCÃO, 2010, p. 48-49).

Nesse sentido, os sujeitos da escola (estudantes e professoras supervisoras) eram incitados a participar de forma interativa nas discussões e diálogos no grupo, conjuntamente com o professor orientador/formador da UFFS, a professora formadora da escola e as licenciandas voluntárias, sendo que buscávamos desenvolver uma parceria entre Universidade e Escola. As estudantes desenvolviam as atividades de pesquisa propostas no projeto, como produção e análise de dados e produção de relatórios de pesquisa, orientadas pelas professoras supervisoras, o professor orientador/formador da UFFS, a professora formadora da escola e as licenciandas voluntárias, as quais auxiliavam e orientavam a pesquisa (DEMO, 2000, p. 10). Eram realizadas leituras em grupo e como tarefa de casa, porém todas as leituras eram sempre discutidas no grupo, para melhor sistematização e compreensão, além da reflexão individual no diário de bordo desenvolvido na escola pelas estudantes e professoras supervisoras. O diário de bordo era utilizado também para a reflexão sobre os encontros e todo o processo de pesquisa.

Nesse caminho (processo de formar, investigar e aprender), torna-se possível a reflexão sobre as práticas docentes, considerada um caminho com potencial formativo, portanto uma reflexão formativa, conforme destaca Güllich (2013). Considerando que a reflexão é um processo demorado e gradual (PORLÁN; MARTÍN, 2001; ALARCÃO, 2010; KIEREPKA; GÜLLICH; WYZYKOWSKI, 2013), buscamos desenvolver a investigação-ação na perspectiva crítica (CARR; KEMMIS, 1988). Nesse sentido, inicialmente é importante a participação de sujeitos mais experientes. A participação de professores e alunos da escola é importante para o estabelecimento de comunidade reflexiva (ALARCÃO, 2010) pela participação de todos os envolvidos na escola, inclusive os pais e dirigentes escolares (CARR; KEMMIS, 1988).

\section{Contribuições de um programa de pesquisa da área de Ciências da Natureza na}

\section{formação de professores e estudantes de ensino médio e ensino fundamental}

O diário de bordo foi utilizado para a narração escrita durante o desenvolvimento do projeto inserido no PICMEL. A sua adoção é baseada em argumentos construídos com aporte 
em teóricos e pesquisas anteriores. Porlán e Martín (2001, p. 52, tradução nossa) descrevem que "o diário deixa de ser exclusivamente um registro do processo reflexivo, para converter-se progressivamente em organizador de uma autêntica investigação profissional", à medida que o professor assuma a reflexão no diário de bordo como caminho formativo. Por meio dos diários, “o professor autoexplora a sua atuação profissional, autoproporciona-se feedback e estímulos de melhoria" (ZABALZA, 1994, p. 10), o que implica a problematização de teorias e práticas, que pode resultar no reconhecimento de problemas na prática docente.

As ideias compartilhadas no coletivo docente podem ser internalizadas. O processo de internalização, definido por Vygotsky (2007, p. 56) como "a reconstrução interna de uma operação externa", de novas ideias teóricas e/ou a partir do diálogo com o outro, contribui para a transformação do pensar do sujeito. Defendemos que, no processo de internalização, pode cumprir papel importante a reflexão, no sentido de reconstrução de ideias externas, pois a produção de conceitos não ocorre a partir da simples memorização, mas em constante processo de recriação na mente do sujeito, que aprende quando assume posição ativa ao conhecer o objeto em estudo (VYGOTSKY, 2008).

Para ocorrer a apropriação da teoria, é necessário o envolvimento do sujeito em interpretá-la e reconstruí-la. Segundo Vygotsky (2008, p. 67), “Ach defende que a formação de conceitos é um processo criativo, e não um processo mecânico e passivo". Portanto, a internalização da teoria não ocorre apenas pela cópia. É necessário o esforço de refletir e reinventar com autenticidade. Isso implica a formação do professor, que precisa ser reconhecido como sujeito que pensa. Nesse processo, o diário de bordo pode desenvolver o exercício de reflexão (PORLÁN; MARTÍN, 2001), auxiliando no processo de internalização de novos conceitos, se acompanhado por teoria.

Dessa forma, com o reconhecimento das possibilidades do diário de bordo, foi proposta a sua adoção pelos integrantes, estudantes e professoras. A finalidade geral desse instrumento dentro do grupo era contribuir para o desenvolvimento da reflexão pelo sujeito.

A partir da leitura dos diários de bordo, foram encontradas narrações sobre os encontros do grupo, as leituras dos referenciais do Educar pela Pesquisa (MORAES, 2002; MORAES; GALIAZZI; RAMOS, 2002; RAMOS, 2002), os documentos analisados (Regimento Referência das Escolas de Ensino Médio Politécnico da Rede Estadual e Regimento Escolar da Escola), a produção dos artigos científicos e acerca de encontros dos Ciclos Formativos em Ensino de Ciências, dois quais participaram as professoras supervisoras do projeto. Defendemos que as narrações evoluem gradativamente de descrições para reflexões (PORLÁN; MARTÍN, 2001; ALARCÃO, 2010; KIEREPKA; GÜLLICH; WYZYKOWSKI, 2013), 
tornando o processo de escrita formativo, o que justifica a adoção do diário de bordo. Essas narrativas dos sujeitos são analisadas na sequência.

Após um tempo de produção dos diários de bordo, identificamos fragmentos que indiciam a reconstrução de concepções sobre pesquisa com base na perspectiva do Educar pela Pesquisa, dado que as professoras descreveram que uma das finalidades da pesquisa é despertar o interesse dos alunos e buscar mais saberes e conhecimentos, possibilitar a construção de novos conhecimentos e proporcionar a aprendizagem de habilidades como o questionamento, a crítica e a argumentação. Tudo isso ajuda a refletir sobre o papel do professor, que se constitui orientador no Educar pela Pesquisa.

Nas palavras da professora Sandra: "esta é então uma das finalidades da pesquisa: despertar o interesse e buscar mais saberes, conhecimentos" (informação verbal). Podemos perceber que a professora reconheceu a autonomia do estudante no Educar pela Pesquisa, quando escreve sobre a importância de que o aluno, auxiliado pelo professor, busque os seus conhecimentos. A construção de conhecimentos é uma das etapas do Educar pela Pesquisa (DEMO, 2000; MORAES, 2002), o que evidencia a aproximação com pressupostos do Educar pela Pesquisa. Em outro excerto, a professora escreve: "através da pesquisa aprendemos descobrir, questionar, analisar, comparar, criticar, avaliar, sintetizar, argumentar e criar. Também construímos novos saberes, conhecimentos" (informação verbal).

A professora Sandra reconhece também o seu papel no ensino pela pesquisa: "é preciso orientar o aluno para que este desenvolva um olhar crítico e reconheça as verdadeiras fontes de informações e conhecimentos" (informação verbal). Reconhece também que Educar pela Pesquisa deve desenvolver estratégias que desafiem os estudantes a pesquisar. Assim, suas ideias situam-se no papel do professor como orientador do processo de ensino e aprendizagem. Entende que o professor não é o detentor de verdades, mas constrói conhecimentos em colaboração com os alunos no processo de pesquisa. Cita que o professor precisa ensinar ao estudante o desenvolvimento da criticidade frente às informações veiculadas pelos meios de comunicação.

Dessa forma, percebemos que o diário de bordo se constitui recurso para escrita sobre as leituras e a experiência de pesquisa que estava sendo vivenciada. E, a partir da análise dos diários, percebemos que os sujeitos incorporavam às suas concepções sobre pesquisa ideias do Educar pela Pesquisa, como a defesa da autonomia do aluno, a crítica à cópia, a relevância da construção dos conhecimentos e a valorização da criticidade dos sujeitos.

Nos diários de bordo das Estudantes, também identificamos indícios de concepções fundamentadas em ideias do Educar pela Pesquisa, à medida que criticaram a cópia, destacaram 
a importância da produção de conclusões e a participação dos estudantes no processo de pesquisa. Fabiana escreveu: "com esses textos que lemos foi escrito as nossas conclusões, as formas de pesquisas, sendo o nosso primeiro trabalho para ser apresentado", deixando explícita a autonomia do grupo, pois destacou a produção de "nossas conclusões" e "o nosso primeiro trabalho" (informação verbal). Depreendemos do excerto, também, a percepção de Fabiana sobre a participação ativa das Estudantes no processo de pesquisa, produzindo seus conhecimentos com protagonismo. Consideramos isso importante, pois os alunos são reconhecidos como sujeitos no Educar pela Pesquisa.

Nos diários das Estudantes, assim como das professoras supervisoras, foi possível identificar descrições das leituras e atividades realizadas nos encontros. Porém, também foi possível identificar concepções em concordância com princípios do Educar pela Pesquisa, o que indica a apropriação de pressupostos do Educar pela Pesquisa. Maria destacou que: "a pesquisa tem um foco de o aluno, ou seja, nós os bolsistas, a pesquisarmos sozinhos e tirarmos nossas conclusões com o professor, apenas orientando, dando um caminho para nós conseguirmos trilhar". É possível perceber a valorização do protagonismo do aluno na construção de conhecimentos. "O saber pensar e o aprender a aprender dependem e exigem capacidade comunicativa, capacidade de argumentação e de elaboração própria" (GALIAZZI, 2003, p. 87).

Maria percebeu também que, na pesquisa realizada no projeto, o grupo produziu conclusões próprias: “a mesma coisa acontece no projeto, temos que pesquisar, ler; para poder ter uma opinião própria" (informação verbal). Esses fragmentos evidenciam que Maria refletiu sobre a experiência vivenciada no projeto. Assim, reconheceu, a partir da análise de vivências no projeto, pressupostos do Educar pela Pesquisa, como a linguagem, a leitura e a escrita (GALIAZZI, 2003, p. 95). Esta reflexão provavelmente só foi possível por meio do estudo do Educar pela Pesquisa, realizado no grupo.

Milena descreveu em seu diário de bordo que as pesquisas realizadas pelos alunos, no contexto escolar, muitas vezes se limitam a cópias, o que não contribui para o desenvolvimento de seu conhecimento: "um professor [...] que saiba exatamente os passos de uma pesquisa [...] as infinitas cópias que os alunos apresentam, em que se apropriam do conhecimento dos outros e não acrescentam nada ao seu intelecto" (informação verbal). Maria, Milena e Fernanda perceberam que a pesquisa não é cópia. Que se faz necessário o questionamento, a partir do qual são produzidos os conhecimentos, conforme indica o fragmento de Fernanda: "pesquisa é questionar-se cada vez mais" (informação verbal). 
Foi possível perceber que as Estudantes reconheceram a relevância da pesquisa. Nas palavras de Miriam: "tivemos conhecimento do projeto, tiramos nossas dúvidas, questionamos. Tendo conhecimento de como a pesquisa é importante" (informação verbal). No diário de bordo de Franciele, foi possível identificar a crítica à cópia: “eu entendi que a gente não pode entrar no primeiro site e copiar tudo, nós temos que ler vários e tirar as informações necessárias de cada um”. Para Franciele, Educar pela Pesquisa é: “para mim, Educar pela Pesquisa é que a gente tem que ler bastante para depois escrever o que entendeu, porque a gente não pode ficar só fazendo cópia de tudo" (informação verbal). É importante destacar a autonomia de Franciele, evidenciada nas afirmações "eu entendi” e "para mim", o que indicia a reflexão e reconstrução de conhecimentos, ideias do Educar pela Pesquisa. Demo (2000) critica a aula que apenas ensina a copiar. Galiazzi (2003, p. 88) descreve os níveis de pesquisa, propostos por Habermas (1989): interpretação reprodutiva; interpretação própria; reconstrução. Dessa forma, inicialmente a pesquisa tende à cópia, mas deve gradativamente atingir níveis de produção própria.

Nesse sentido, a crítica às cópias e a proposição da importância do questionamento podem ser indícios de ideias internalizadas pelos sujeitos. "A base da educação escolar é a pesquisa, não a aula, ou o ambiente de socialização, ou a ambiência física, ou o mero contato entre professor e aluno" (DEMO, 2000, p. 6). Fernanda afirma: "Educar pela Pesquisa para mim, é como uma aula diferente [...] A pesquisa serve para que possamos entender melhor e de maneira mais clara alguns assuntos, tornando-nos pessoas mais autônomas" (informação verbal).

Maria, conforme discutido acima, afirmava que no Educar pela Pesquisa a função do professor é orientar os alunos na produção de suas próprias conclusões. Fabiana descreveu ideias semelhantes: "Educar pela Pesquisa é uma forma de entender a pesquisa com suas palavras ou pesquisar as coisas e ter uma noção do assunto para escrever com suas palavras e ter questionamento com o assunto" (informação verbal). As considerações sobre a importância da produção de conclusões próprias e escrever com suas palavras são indícios da necessária autonomia do aluno, que foi reconhecido pelos sujeitos. "Pesquisa é coletar dados, ter questionamento no assunto e ir atrás das respostas a partir dos questionamentos" (informação verbal). Essas ideias foram provavelmente construídas a partir de autores como Demo (2000), Moraes, Galiazzi e Ramos (2002), que também propõem o questionamento no Educar pela Pesquisa, evidenciando a apropriação de ideias do Educar pela Pesquisa.

Dessa forma, depreendemos da análise dos diários de bordo de participantes do projeto (estudantes e professoras), conforme indícios apresentados, que este é um instrumento que pode 
contribuir, por meio da reflexão, no processo de internalização de conceitos e formas de pesquisar, provavelmente decorrente das leituras, reflexão individual e também compartilhada, porém a importância do diário de bordo pode residir em possibilitar uma maior sistematização das ideias.

Reiteramos que o projeto trouxe contribuições à formação dos sujeitos, a constar: desenvolvimento da escrita reflexiva; apropriação de ideias sobre o Educar pela Pesquisa, sobre sua relevância e possibilidades de desenvolvimento; reconstrução de concepções sobre o ensino pela pesquisa e reconhecimento do processo de pesquisa.

Também destacamos a relevância do projeto inserido no PICMEL para a introdução dos sujeitos na prática da pesquisa, que pode ter se constituído em uma oportunidade para a aprendizagem dos procedimentos de pesquisa, com a possibilidade de desenvolvimento desta habilidade. Nicolini e Moraes (2005) propõem o Educar pela Pesquisa com o desenvolvimento de projetos de aprendizagem em âmbito escolar.

Propomos a importância do projeto como espaço de constituição de novos conhecimentos sobre o processo de pesquisa, pela experiência em si, bem como pela discussão da temática do projeto, o Educar pela Pesquisa como teoria pertinente para orientar a pesquisa escolar. Vygotsky (2008) defende que o sujeito aprende na interação com o outro. O coletivo é importante para a constituição de novos conhecimentos e habilidades pelo sujeito, por isso é importante o diálogo em grupos colaborativos.

\section{Considerações finais}

A análise do contexto aqui situado nos permite propor a necessidade de constituir coletivos colaborativos para a problematização conjunta, pois a reflexão é uma capacidade construída e se enriquece pelo diálogo. Em relação ao grupo constituído na escola por meio da proposta do PICMEL e descrito neste texto, percebemos que aos poucos foi se constituindo reflexivo, na medida em que as leituras e discussões foram trazendo inquietações e proporcionaram o reconhecimento e a reconstrução de concepções sobre o ensino pela pesquisa.

Defendemos que o diário de bordo é um instrumento que pode ter contribuído, por meio da reflexão, no processo de internalização de conceitos e formas de pesquisar, uma vez que identificamos indícios da reconstrução de concepções de pesquisa com base na perspectiva do Educar pela Pesquisa, provavelmente decorrente das leituras, reflexão individual e também compartilhada, porém a importância do diário de bordo pode residir em possibilitar uma maior sistematização das ideias, além do registro. 


\section{\#tear}

Portanto, reforçamos o nosso argumento inicial de que o processo reflexivo impulsiona a internalização de concepções, reflexão individual ou no coletivo, em que um favorece o outro. Inicialmente não podemos afirmar que os sujeitos tenham se apropriado das leituras, pois se caracterizavam em descrições das leituras, assim como dos encontros do projeto e dos Ciclos Formativos (GEPECIEM), eram, em geral, cópias dos referenciais, porém, com o tempo, foi possível perceber ideias reconstruídas pelos sujeitos acerca do Educar pela Pesquisa e do processo de pesquisa vivenciado.

Em relação a entendimentos sobre o Educar pela Pesquisa, percebemos a valorização do protagonismo do aluno, em meio à crítica ao ensino reprodutivo. É enfatizada a importância da reconstrução dos conhecimentos na pesquisa, ao invés da mera cópia. O professor é reconhecido como orientador da pesquisa, com o resgate da autonomia do aluno no processo pedagógico. Para isso, é proposto o desenvolvimento da problematização, da formulação de respostas e da comunicação de argumentos, em contextos de ensino dialógico. Ganham destaque as curiosidades formuladas pelos alunos, a leitura e a escrita. Desse modo, identificamos indícios de pressupostos que norteiam o Educar pela Pesquisa, o que aponta para a possibilidade de utilizá-lo para a transformação das concepções de professores em formação inicial e continuada, com a superação de visões tradicionais, o que nos permite reafirmar também a relevância de grupos de formação continuada, enquanto espaços que auxiliam na transformação de concepções de docência e quiçá de práticas pedagógicas.

Os integrantes do grupo tiveram a oportunidade de vivenciar o desenvolvimento de uma pesquisa ao desenvolver as ações do projeto e também por meio do estudo e investigação de concepções sobre o Educar pela Pesquisa, tema do projeto. Dessa forma, o projeto promoveu o desenvolvimento de habilidades de pesquisa, a reconstrução de teorias sobre a pesquisa, bem como o desenvolvimento da reflexão, no intuito de formar sujeitos mais autônomos e reflexivos.

\section{THE CONTRIBUTION OF TEACHING AND LEARNING PROCESSES WITH RESEARCH IN THE TRAINING OF TEACHERS AND STUDENTS OF BASIC EDUCATION}

Abstract: In this text we describe an experience in the development of a project at PICMEL from FAPERGS scholarship. The project was developed from October 2014 to November 2015 in a school from the city of Guarani das Missões/RS, in cooperation with Federal University of Fronteira Sul (UFFS), from Cerro Largo/RS, named: "The scientific-school research in Basic Education and the recognition in the area of Biologic Science". The participants of the group, the objectives and the actions from the program are reported, as well as the discussion on some contributions of the program, the teachers and students training from the investigation of the logbook from the group. We sustain that the logbook is an instrument that can contribute 
through reflection in the process of internalization of concepts and ways of research, as we identify clues of the research concepts reconstruction based on Educate through Research: promotion of the students' prominence; importance of knowledge reconstruction; teachers as research advisors; students' empowerment recover; importance of the curiosities formulated by students, reading and writing. In this way, we identify evidences of assumptions that orientate the Educate through Research which indicate to the possibility of the transformation of the concepts of teachers in continuing education, with the overcoming of traditional views, and allows us to confirm also the importance of continuing education groups as spaces that help in the changing of concepts of teaching and pedagogical practices.

Keywords: Educate Through Research. Logbook. Reflection. Internalization.

\section{Referências}

ALARCÃO, Isabel. Professores reflexivos em uma escola reflexiva. 7. ed. São Paulo: Cortez, 2010.

BAGNO, Marcos. Pesquisa na escola: o que é como se faz. 23. ed. São Paulo: Edições Loyola, 2009.

CARR, Wilfred; KEMMIS, Stephen. Teoría crítica de la enseñanza: investigación-acción en la formación del profesorado. Barcelona: Martinez Roca, 1988.

CHAVES, Sílvia Nogueira; ARAGÃO, Rosália Maria Ribeiro de. Problematizar, questionar ou contestar? A necessidade do diálogo na formação docente. In: Reunião Anual da Associação Nacional de Pesquisa e Pós-graduação em Educação, 24., 2001, Caxambu.

Anais... Caxambu: ANPED, 2001. p.1-17.

DEMO, Pedro. Educar pela Pesquisa. 4. ed. Campinas, São Paulo: Autores Associados, 2000.

FAPERGS/CAPES. EDITAL FAPERGS 03/2014. Acordo CAPES/FAPERGS. Programa de Iniciação em Ciências, Matemática, Engenharias, Tecnologias Criativas e Letras - PICMEL. 2014.

FRISON, Lourdes Maria Bragagnolo. Pesquisa como Superação da Aula Copiada. In: MORAES, Roque; LIMA, Valderez Marina do Rosário (orgs.). Pesquisa em sala de aula: Tendências para a educação em novos tempos. Porto Alegre: EDIPUCRS, 2002.

GALIAZZI, Maria do C. Educar pela Pesquisa: ambiente de formação de professores de ciências. Ijuí: Ed. UNIJUÍ, 2003.

GÜLLICH, Roque Ismael da Costa. Investigação-Formação-Ação em Ciências: um caminho para reconstruir a relação entre livro didático, o professor e o ensino. Curitiba: Editora Prismas Ltda, 2013.

IBIAPINA, I. M. L. de M. Pesquisa colaborativa: investigação, formação e produção de conhecimentos. Brasília: Líber Livro Editora, 2008. 
KIEREPKA, Janice Silvana Novakowski; GÜLLICH, Roque Ismael da Costa; WYZYKOWSKI, Tamini. A constituição docente em Ciências através do desenvolvimento de narrativas. In: ENCONTRO NACIONAL DE PESQUISA EM EDUCAÇÃO EM CIÊNCIAS, 10., 2013, Águas de Lindoia. Atas ... Águas de Lindóia: ABRAPEC, 2013. p. 18.

LÜDKE, Menga; ANDRÉ, Marli E. D. A. Pesquisa em educação: abordagens qualitativas. São Paulo: EPU, 2011.

MORAES, Roque; GALIAZZI, Maria do Carmo; RAMOS, Maurivan G. Pesquisa em sala de aula: fundamentos e pressupostos. In: MORAES, Roque; LIMA, Valderez Marina do Rosário (orgs.). Pesquisa em sala de aula: Tendências para a educação em novos tempos. Porto Alegre: EDIPUCRS, 2002.

MORAES, Roque. Educar pela Pesquisa: exercício de aprender a aprender. In: MORAES, Roque; LIMA, Valderez Marina do Rosário (orgs.). Pesquisa em sala de aula: Tendências para a educação em novos tempos. Porto Alegre: EDIPUCRS, 2002.

NICOLINI, Cristiane Antonia Hauschild; MORAES, Roque. Educar pela Pesquisa com projetos de aprendizagem: algumas experiências. In: ENCONTRO IBERO-AMERICANO DE COLETIVOS ESCOLARES E REDES DE PROFESSORES QUE FAZEM INVESTIGAÇÃO NA SUA ESCOLA, 4., 2005. Lajeado. Anais ... Lajeado: Univates, 2005. p.1-8.

PORLÁN, Rafael; MARTÍN, José. El diario del profesor: um recurso para investigación em el aula. Díada: Sevilla, 2001.

RAMOS, Maurivan Güntzel. Educar pela Pesquisa é Educar para a Argumentação. In: MORAES, Roque; LIMA, Valderez Marina do Rosário (orgs.). Pesquisa em sala de aula: Tendências para a educação em novos tempos. Porto Alegre: EDIPUCRS, 2002.

VYGOTSKY, Lev Semyonovich. A Formação Social da Mente: o desenvolvimento dos processos psicológicos superiores. Tradução de José Cipolla Neto, Luís Silveira Menna Barreto, Solange Castro Afeche. 7. ed. São Paulo: Martins Fontes, 2007.

. Pensamento e Linguagem. Tradução de Jefferson Luiz Camargo. 4. ed. São Paulo: Martins Fontes, 2008.

ZABALZA, Miguel Ángel. Diários de aula. Tradutores: José Augusto Pacheco e José Machado. Porto: Porto Editora, 1994.

ZANON, Lenir Basso. Interações de licenciandos, formadores e professores na elaboração conceitual de prática docente: módulos triádicos na licenciatura de Química. 2003. Tese (Doutorado em Educação) - Faculdade de Ciências Humanas, Universidade Metodista de Piracicaba, Piracicaba, 2003. 